\title{
Use of an intravenous port catheter for the delivery of intrathecal morphine in a terminally ill cancer patient with pain
}

\author{
Jamil S. Anwari, FFARCS, Kamel Romdhane, MD.
}

\begin{abstract}
نستعرض في هذا التقرير حالة مريضة سرطان مصابه بمرض عضال

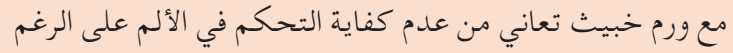

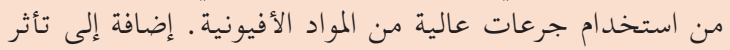

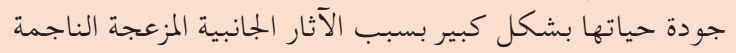

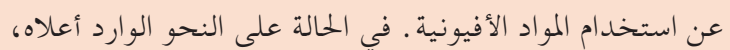

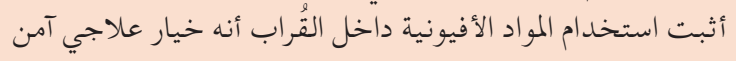

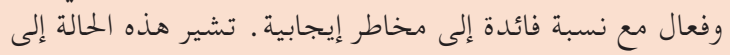

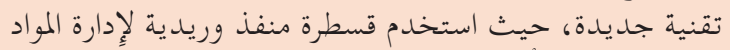

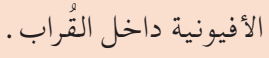

We present a case of a terminally ill cancer patient with metastasis who was suffering from inadequate pain control despite high doses of systemic opioid administration. In addition, her quality of life was significantly impaired due to opioid-induced troublesome side effects. In the situation as above, intrathecal opioid administration has established as a safe and effective therapeutic option with a positive benefit-risk ratio. This case reports a novel technique, where an intravenous port catheter was used to administer intrathecal opioid.

Neurosciences 2020; Vol. 25 (5): 399-402 doi: $10.17712 / n s j .2020 .5 .20200009$

Department of Anaesthesia \& Pain, Prince Sultan Military Medical City, Riyadh, Kingdom of Saudi Arabia

Received 20th February 2020. Accepted 14th June 2020.

Address correspondence and reprint request to: Dr. Jamil S. Anwari, Department of Anaesthesia \& Pain, Prince Sultan Military Medical City, Riyadh, Kingdom of Saudi Arabia. E-mail: jsanwari@hotmail. com

ORCID ID: https://orcid.org/0000-0002-1850-1239 any terminally ill patients with malignant pain, despite high doses of systemic opioids suffer from agony. Advanced analgesic strategy such as intrathecal drug delivery (ITDD) system is employed to deliver opioid directly to the spinal cord. ${ }^{1}$ This technique provides superior pain control, hence renders both, good quality of life and death to the patient. In a situation when ITTD system not available, alternate methods are used to deliver a drug to the CSF.

Case Report. Patient information and clinical examination. A 39-year-old terminally ill lady with metastatic breast cancer presented with moderately severe upper abdominal pain. The pain started about 4 months prior due to metastasis in her liver and spleen. Initially, the pain was well controlled with a transdermal fentanyl patch (TFP). Later, despite a high dose of

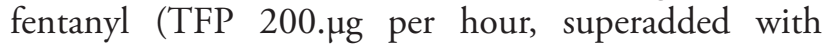
frequent sublingual 100.ug fentanyl doses), her pain was not well controlled. In addition, she was having mild drowsiness fluctuating to almost a comatose state, moderately severe itching, nausea, and constipation. She also gave a history of orthopnea and felt less distress when sitting and in a left lateral position. She could walk a few steps with support and was continent of urine and stool. According to her oncologist, her life expectancy was less than 2 months. Upon a physical examination, she was $56 \mathrm{Kg}$, looked pale, cachectic, and distressed. She was well educated and orientated and expressed her complaints in broken sentences. Her abdomen was distended due to massive hepato-splenomegaly.

Diagnostic evaluation Blood hematology and biochemistry were within normal limits. Although the liver function tests were deranged, the prothrombin time was normal. A radiological investigation revealed massive hepato-splenomegaly and metastasis in the long bones but chest was clear.

Intervention for the relief of pain. She signed the informed consent for the insertion of a port catheter as 


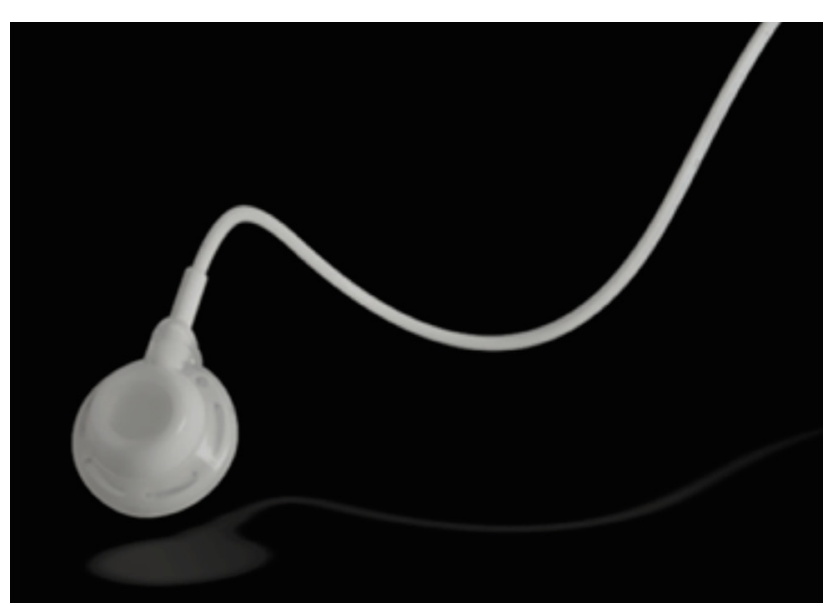

Figure 1 - BardPort $^{\mathrm{TM}}$ intravenous catheter.

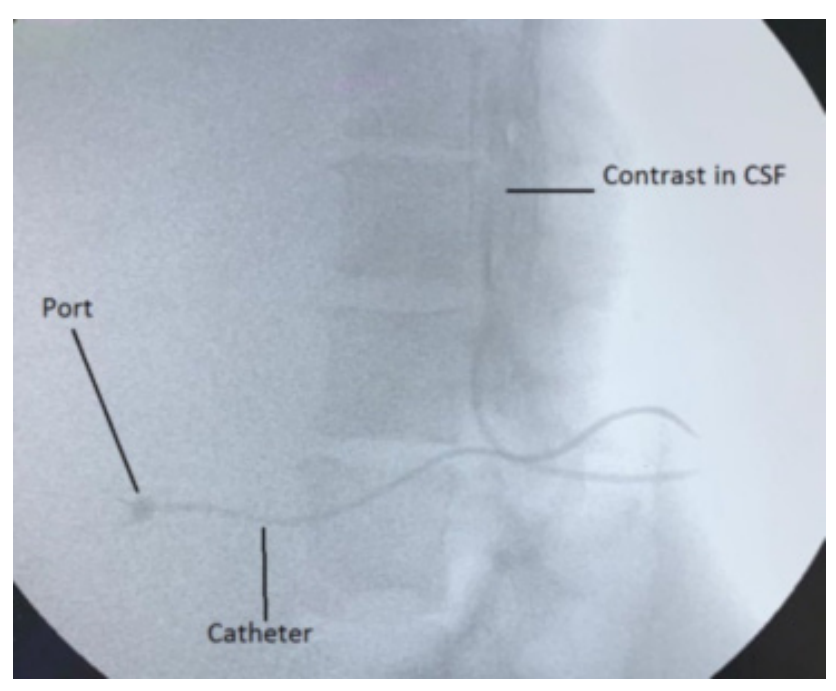

Figure 2 - Radio-contrast showing port catheter and its dispersion in the CSF

a route for the administration of intrathecal morphine. With a fasting period of 6 hours for solid food, she was brought into the operating theatre and placed on an operating table in the left lateral position with 2 pillows under her head. Routine monitoring (such as ECG, $\mathrm{BP}$, and $\mathrm{SpO}_{2}$ ) was commenced, and intravenous access on the arm was secured, through which a prophylactic dose of ceftriaxone $(1.0 \mathrm{G})$ was given. Both operators (JSA \& KR) and the assisting nurse took strict aseptic precautions. A wide area of skin was double cleaned with $2 \%$ chlorhexidine and $70 \%$ alcohol, which was isolated with sterile drapes. The procedure was done under local anesthesia (lignocaine $1.0 \%$ with adrenaline $1: 200,000)$. Sterile procedural instruments were place on the trolley, including a BardPort ${ }^{\mathrm{TM}}$, an implantable port with a $6.6 \mathrm{~F}$ catheter (BARD access system Inc. Utah USA) (Figure 1) and an epidural minipack of Portex $^{\oplus}$ (Smith medical int. USA). The procedure was carried out under fluoroscopic guidance. An epidural Tuohy needle (18.G) was inserted between the L2 and L3 inter-spinous space and advanced, using the loss of resistance to air technique till reaching the epidural space. The Tuohy needle was further advanced for a few millimeters till a free flow of CSF appeared. The skin to subarachnoid space distance was noted. The Seldinger guide wire (GW) from the BardPort was inserted through the tapered end of a "J" straightener and through the Tuohy needle.

Before pushing the GW further to appear through the bevel opening, the patient was warned about current-like sensations in her lower limbs. In the fluoroscopic view, the GW appeared through the needle, which was further pushed about $4 \mathrm{cms}$ in the subarachnoid space. The patient felt the paresthesia, but did not require any analgesic. Keeping the GW in place, the Tuohy needle was removed. Using a surgical scalpel blade No. 11, a stab incision was made from the exit point of the GW, $1.5 \mathrm{cms}$ deep to the skin. Then, the operator took the BardPort ${ }^{\mathrm{TM}}$ vessel dilator and sheath as a unit, and a length equal to the previously measured skin-subarachnoid distance was marked with sterile ink. This unit was then advanced up to the mark over the exposed GW. While the sheath was held in place, the dilator and GW were removed together. The CSF appeared through the proximal end of the sheath. The BardPort $^{\mathrm{TM}}$ catheter $(6.6 \mathrm{~F})$ was inserted into the sheath and advanced $4 \mathrm{cms}$ in the subarachnoid space. When the CSF appeared from the proximal end of the catheter and its tip position was fluoroscopically confirmed, the sheath was then peeled away from the catheter. A subcutaneous pocket for the port was created below the right costal margin over the anterior axillary line. Through the stab incision made earlier (at the catheter entry site), the tip of the tunneler was advanced to the port pocket site. The free end of the catheter was then attached to the tunneler barb, and the tunneler was completely pulled through to the pocket port and then detached from the catheter. The air from the port was removed by flushing with saline and placed in a subcutaneous pocket. The excess length of the catheter was cut and connected with the port. The port was secured with stitches, and the skin was sutured to close the port pocket. One $\mathrm{ml}$ of radio-opaque contrast (Iohexol 350) was injected trans dermally into the port, which confirmed its spread into the CSF (Figure 2). We used $2.0 \mathrm{ml}$ of preservative-free (PF) morphine $(0.5 \mathrm{mg} /$ 
$\mathrm{ml})$ mixed with $1.0 \mathrm{ml}(50 \mu \mathrm{g})$ of fentanyl as the first intrathecal dose. The patient's pain improved from $8 / 10$ to $2 / 10$ in less than 15 minutes.

Follow up and outcome. Subsequently, the patient received once day intrathecal $\mathrm{PF}$ morphine $(2.0 \mathrm{ml}$, or $1.0 \mathrm{mg}$ ) without fentanyl. She was allowed to take a fentanyl sublingual tablet $(100 \mu \mathrm{g})$ for breakthrough pain. During subsequent days, her pain was well controlled with minimal side effects with the once a day intrathecal morphine. Throughout, she remained apyrexial with normal white cell count. On the 18th day after the insertion of the intrathecal BardPort ${ }^{\mathrm{TM}}$, she peacefully expired in the presence of her relative.

Discussion. Breast cancer is a common malignancy among Saudi females, with a prevalence of $21.8 \%$ and around 930 new cases of breast cancer diagnosed each year. ${ }^{2}$ Cancer pain is a global health issue. ${ }^{3}$ A survey conducted on adult cancer patients in an oncology unit of a teaching hospital in Riyadh found that 50\% of patients reported moderate to severe cancer pain. ${ }^{4}$ The standard of care for cancer patients is set by the Joint Commission on Accreditation of Healthcare Organization, which states, "No cancer patient should live or die with unrelieved pain". 5 The expectations of terminally ill patients, their relatives, and care providers are akin to such a standard. A systemic review exploring the component of "good death" looked into 36 studies and revealed that all the stakeholders considered pain-free status a top priority. ${ }^{6}$ Eighty percent of patients with advanced cancer pain who received oral or transdermal opioid achieved adequate pain control. However, for the remaining $20 \%$ of patients, interventional treatment was required. ${ }^{7}$

Although our patient reached the third step of the WHO analgesic ladder, her condition was miserable. Her pain, despite the high dose of transdermal fentanyl, was not well controlled. In addition, she suffered from many troublesome opioid side effects. Therefore, we decided to offer her the "fourth step". ${ }^{7}$ One option was to perform an ablative procedure, such as a celiac plexus or a splanchnic nerve neurolysis. These procedures are usually carried out under fluoroscopic guidance and require the patient to be in a prone position. In our case, it was not possible for her to lie in the required position.

The second option was to directly administer the opioid into the spinal cord. In 1973, Tony Yaksh discovered that the opioid receptors in the spinal cord provided the scientific rationale for this form of treatment. ${ }^{8} \mathrm{~A}$ few years later, Wang et $\mathrm{al}^{9}$ first reported the successful use of intrathecal morphine for cancer pain. Henceforth we opt for administering spinal opioid through an intrathecal route. As compared to the epidural, the intrathecal administration route offers lower doses and lower risks of catheter migration and infection. Moreover, as compared to a percutaneous intrathecal catheter, the risk of meningitis is further reduced with a totally implanted catheter with a subcutaneous injection port. ${ }^{10}$ Such devices are commercially available (e.g., Codman 3000. Codman and Shurtleff, Inc., Raynham, MA, USA), but are not available at our institution. One of us (KR) has had good experience in using an implantable port pediatric intravenous access catheter (BardPort ${ }^{\mathrm{TM}}$. Bard Access Systems, Inc. UT. USA) as an intrathecal catheter for administering opioid in terminally ill cancer patients with pain. We decided to use this option. We searched Google and PubMed and could not find any report such as ours. Her pain was adequately controlled, and the fentanyl-induced side effects were significantly reduced with a daily administration of intrathecal morphine $(1.0 \mathrm{mg})$. One week later, the morphine dose was increased to $1.5 \mathrm{mg}$ daily. Throughout the period after the insertion of the intrathecal port catheter, she (and her family) acknowledged good analgesia, maintained good communication, and remained apyrexial, and the opioid-induced side effects were minimal.

Acknowledgement. We are thankful for the patient's family for giving their consent to publish this case report on the assurance that patient's identification will not be disclosed. We are also grateful to Dr Mujtaba Khan (Consultant Radiologist) at our hospital for his kind review of the radiograph. We are also thankful to Scribendi Inc. for editing our manuscript.

\section{References}

1. Stearns LM, Abd-Elsayed A, Perruchoud C, Spencer R, Hammond K, Stromberg K, et al. Intrathecal Drug Delivery Systems for Cancer Pain: An Analysis of a Prospective, Multicenter Product Surveillance Registry. Anesth Analg 2020; 130: 289-297.

2. Alotaibi RM, Rezk HR, Juliana CI, Guure C. Breast cancer mortality in Saudi Arabia: Modeling observed and unobserved factors. PLoS One 2018; 13: e0206148.

3. World Health Organization. Access to Controlled Medications Programme: Framework. Geneva (CH): World Health Organization; 2007. Accessed January 2020. Available at: http://www.who.int/medicines/areas/quality_safety/ Framework_ACMP_withcover.pdf

4. Al-Rowaili A, Al-aqeel SA, Al-Naim LS, Al-Diab AI. Appropriateness of cancer pain management in Saudi teaching hospital. GulfJ Oncolog 2009; : 37-43.

5. levy MH. Pain control in patients with cancer. Oncology (Williston Park) 1999; 13: 9-14. 
6. Meier EA, Gallegos JV, Montross-Thomas LP. Depp CA, Irwin SA, Jeste DV. Defining a good death (successful dying): Literature Review and a call for research and public dialogue. Am J Geriatr Psychiatry 2016; 24: 261-271.

7. Bottros MM, Christo PJ. Current perspectives on intrathecal drug delivery. J Pain Res 2014; 7: 615-626.

8. Yaksh TL, Rudy TA. Analgesia mediated by a direct spinal action of narcotics. Science 1976; 192: 1357-1358.
9. Wang JK, Nauss LA, Viars P. Pain relief by intrathecally applied morphine in man. Anesthesiology 1979; 50: 149-151.

10. Lebeaux D, Fernández-Hidalgo N, Chauhan A, Lee S, Marc Ghigo J, Almirante B, et al. Management of infections related to totally implantable venous-access ports: challenges and perspectives. Lancet Infect Dis 2014; 14: 146-159.

\section{Statistics}

Excerpts from the Uniform Requirements for Manuscripts Submitted to

Biomedical Journals updated November 2003.

Available from www.icmje.org

Describe statistical methods with enough detail to enable a knowledgeable reader with access to the original data to verify the reported results. When possible, quantify findings and present them with appropriate indicators of measurement error or uncertainty (such as confidence intervals). Avoid relying solely on statistical hypothesis testing, such as the use of $P$ values, which fails to convey important information about effect size. References for the design of the study and statistical methods should be to standard works when possible (with pages stated). Define statistical terms, abbreviations, and most symbols. Specify the computer software used. 